\title{
Cooperativity in Binding of Aliphatic Diamines by Bis(Zn(II)porphyrin) Receptor with Moderately Flexible Linkers
}

\author{
Anamarija Briš, Pavle Trošelj, Davor Margetić*
}

\author{
Laboratory for physical organic chemistry, Division of organic chemistry and biochemistry, Ruđer Bošković Institute, Bijenička c. 54, HR-10000, Zagreb, Croatia \\ * Corresponding author's e-mail address: margetid@irb.hr
}

RECEIVED: November 27, 2017 * REVISED: April 5, 2018 * ACCEPTED: April 6, 2018

THIS PAPER IS DEDICATED TO PROF. MLADEN ŽINIĆ ON THE OCCASION OF HIS 70

Abstract: Complexations of bis(Zn(II)porphyrin) receptor possessing moderately flexible linkers with aliphatic $\alpha, \omega$-diamines was studied by UVvis and NMR spectroscopy. The strongest binding was identified for 1,8-diaminooctane, with the binding constant by one order of the magnitude larger than the next diamine homologue 1,7-diaminoheptane.

Keywords: host-guest interactions, supramolecular chemistry, bis-porphyrin, complexation, binding constant, UV-Vis.

\section{INTRODUCTION}

B IS-PORPHYRIN (BP) systems represents one of the commonly used geometries for study of supramolecular self-assembly processes and artificial photosynthesis. This ditopic (divalent) receptor system is composed of two porphyrin moieties separated by linker group, which could vary in conformational flexibility. ${ }^{[1]}$ One of the advantages of bisporphyrinic systems over mono-porphyrins is in the additional strength of self-assembly with bidentate $\mathrm{N}$-donor ligands, due to cooperativity effect. ${ }^{[2]} A$ number of examples of BPs exploit ZnP-pyridine axial coordination ${ }^{[3]}$ with aromatic $\mathrm{N}$-donors as a mode of self-assembly, ${ }^{[4]}$ whereas their complexation with aliphatic diamines and cyclic diamines is less explored. For instance, molecular chirality of chiral diamines was probed through the coordination with Zn(II)bis-porphyrin. ${ }^{[5]}$ DABCO was used by Johnston for complexations of bisporphyrin 1 with freely rotating linker (Chart 1). ${ }^{[6]}$ Intramolecular 1:1 complex DABCO@1 has $K_{\mathrm{a}}=8.1 \times 10^{7} \mathrm{M}^{-1}$ in $\mathrm{CHCl}_{3}$, and for open 2:1 complex $\mathrm{DABCO}_{2} @ 1 K_{\mathrm{a}}=2.7 \times 10^{9}$ $\mathrm{M}^{-1}$ shows a large increase in comparison to model monoPorph@quinuclidine $K_{\mathrm{a}}=2.5 \times 10^{5} \mathrm{M}^{-1}$ the large $K_{\mathrm{a}}$ are obtained by rotational freedom, systems need only be moderately preorganized to obtain large $K_{\mathrm{a}}$.
Furthermore, Ballester et al. prepared a series of bisporphyrin receptors 2 with isophthalic acid as semirigid linker. ${ }^{[7,8]}$ Substitution in $o^{-}, m$ - and $p$ - positions of phenylporphyrin gives receptors with different spatial arrangement of porphyrin moieties which differ in complexation behavior with DABCO. In the case of melamine spaced bis-porphyrins 3-5, conformational mobility of receptors with free rotation around the single bonds was studied during their complexation with a series of aliphatic $\alpha, \omega$-diamines. A selectivity for short diamines by sterically less hindered bis-porphyrin was observed by Carofiglio. ${ }^{[9]}$ It was found that the exciton coupling between two porphyrinic chromophores decreases with the increase of the chain length of the diamine. Coupling also depends on the distance and the dihedral angle between the two porphyrin units. ${ }^{[10]}$ Complexation of diamines with bisporphyrin system possessing the Tröger's base linker 6 studied by Crossley showed higher selectivity for short diamines, which gradually decreases with the size of diamine. ${ }^{[11]}$ Sanders ${ }^{[12]}$ has shown that binding of DABCO with mono and bis-porphyrins 7 leads to opposite effects: bathochromic shift of maximum in monoporphyrins and hypsochromic shift in bis-porphyrins due to $\pi-\pi$ interactions. Semi-rigid spacer $\mathbf{8}$ with glycoluril backbone

(c) Br $\mathbf{B Y}$ This work is licensed under a Creative Commons Attribution 4.0 International License. 


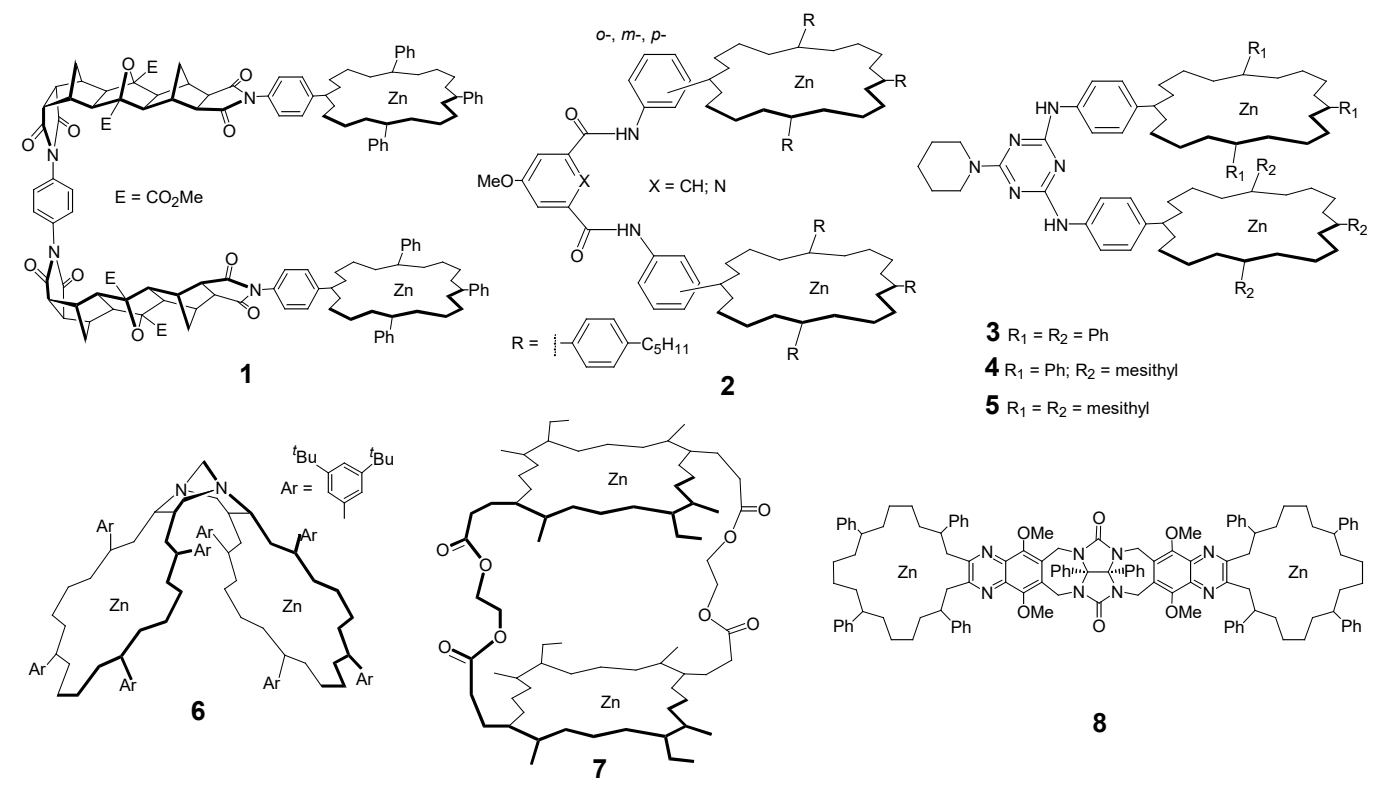

Chart 1. Representative bis-porphyrin systems (only the skeleton structures of porphyrin systems are shown).

was used by Norrehed ${ }^{[13]}$ in complexations with $\alpha, \omega$ diamines: 1,6-diaminohexane, 1,8-diaminooctane, 1,12diaminododecane $\left(K_{\mathrm{a}}=10^{6}\right)$ and 1,20-diaminoeicosane $\left(K_{\mathrm{a}}=10^{5}\right)$ in dichloromethane. The same spacer was also used for determination of relative stereochemistry. ${ }^{[14]}$

Here we present results of supramolecular selfassembly of bis-porphyrin $\mathbf{9}^{[15]}$ and a series of ditopic guests such as diamines. The aim of this study was to investigate hostguest interactions of diamines, wanting to establish if there is any size selectivity as for the specific recognition of diamines and other interesting molecular recognition properties.

\section{RESULTS AND DISCUSSION}

Coordination of bis-porphyrin 9 as well as model porphyrins $\mathrm{Zn}\left(\mathrm{T}-p-\mathrm{CH}_{3} \mathrm{FP}\right) \mathbf{1 1}$ and $\mathbf{1 0}$ (Chart 2) with nitrogen-donating guests was studied by spectrophotometric methods. Host $\mathbf{9}$ was designed to have its [5]polynorbornane linker providing appropriate orientation of the two porphyrin rings, whereas propyl chains allow a degree of conformational freedom to adjust to the host size and shape enabling more efficient binding. In earlier designs of polynorbornane bis-porphyrin systems, conformational flexibility was introduced by cyclohexene molecular hinges. ${ }^{[16,17]}$

Bis-porphyrinic host 9 could assume a diversity of conformations in solution, which are in rapid equilibrium. The extended ( $E$ ) and bent (B) conformations are two extremes. In the presence of ditopic ligand guests, these can form various complexes. Complexation equilibria involved in the coordination of diamine guests to host $\mathbf{9}$ and schematic representation of formation of $1: 1,1: 2$ and $2: 2$ species are depicted in Scheme 1. ${ }^{[6,18]}$
The strength of noncovalent interactions of model porphyrins $\mathbf{1 0}$ and $\mathrm{Zn}\left(\mathrm{T}-p-\mathrm{CH}_{3} \mathrm{FP}\right) \mathbf{1 1}$ was determined by complexations with acyclic propylamine and cyclic quinuclidine by UV-Vis titrations in toluene at room temperature (Table 1). In the course of all monoporphyrin titrations, a characteristic bathochromic shift of Soret and $Q$ bands was observed as the result of formation of receptor-substrate complex. Figure 1 depicts these changes for titration of the porphyrin $\mathbf{1 0}$ with propylamine. Decrease of Soret band at $425 \mathrm{~nm}$ is associated with the formation of new absorption maximum at $431 \mathrm{~nm}$. A clear isosbestic point at $428 \mathrm{~nm}$ indicates the equilibrium between two states: free porphyrin $\mathbf{1 0}$ and propylamine@10 complex.

Values obtained in titrations with $\mathbf{1 0}$ and $\mathbf{1 1}$ are in agreement with binding contants for monoporphyrins given in the literature. ${ }^{[22]}$ Propylamine has high binding constant due to its high basicity ${ }^{[23]}$ and lacks the steric interactions during the binding to monoporphyrins. Cyclic quinuclidine has $K_{\mathrm{a}}$ larger by one order of magnitude than acyclic propylamine due to reduced repulsion between substituents and porphyrinic macrocycle. The binding constants values for $\mathrm{Zn}\left(\mathrm{T}-p-\mathrm{CH}_{3} \mathrm{FP}\right) \mathbf{1 1}$ and porphyrin $\mathbf{1 0}$ are almost identical, which indicate that the norbornane moiety in $\mathbf{1 0}$ is distant from the zinc-amine coordination site and therefore does not have influence on the binding.

The strength of noncovalent interactions with bisporphyrin 9 was determined with acyclic $\alpha, \omega$-diamines of general formula $\mathrm{H}_{2} \mathrm{~N}\left(\mathrm{CH}_{2}\right)_{n} \mathrm{NH}_{2}, n=2-8$, as well as with cyclic diamines: pyrazine, 4,4'-bipyridine and 1,4diazabicyclo[2.2.2] octane (DABCO). In such way, conformational flexibility of bis-porphyrin 9 was experimentally 
Hosts

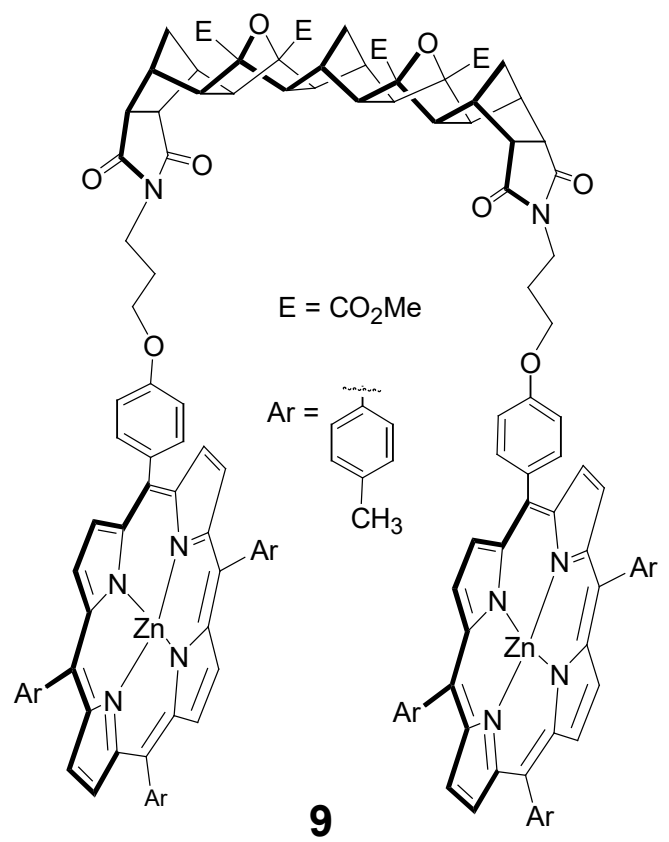

\section{Model hosts}

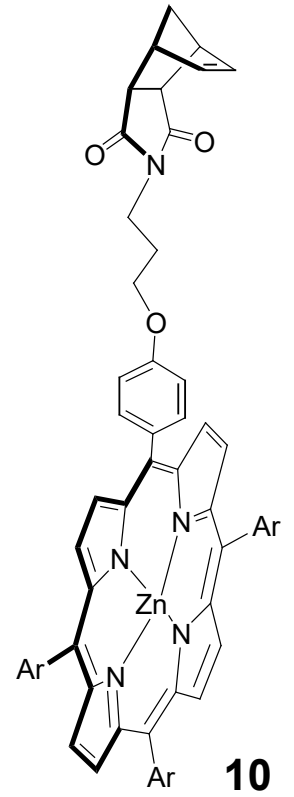

Chart 2. Structures of host 9 and model hosts 10 and 11.

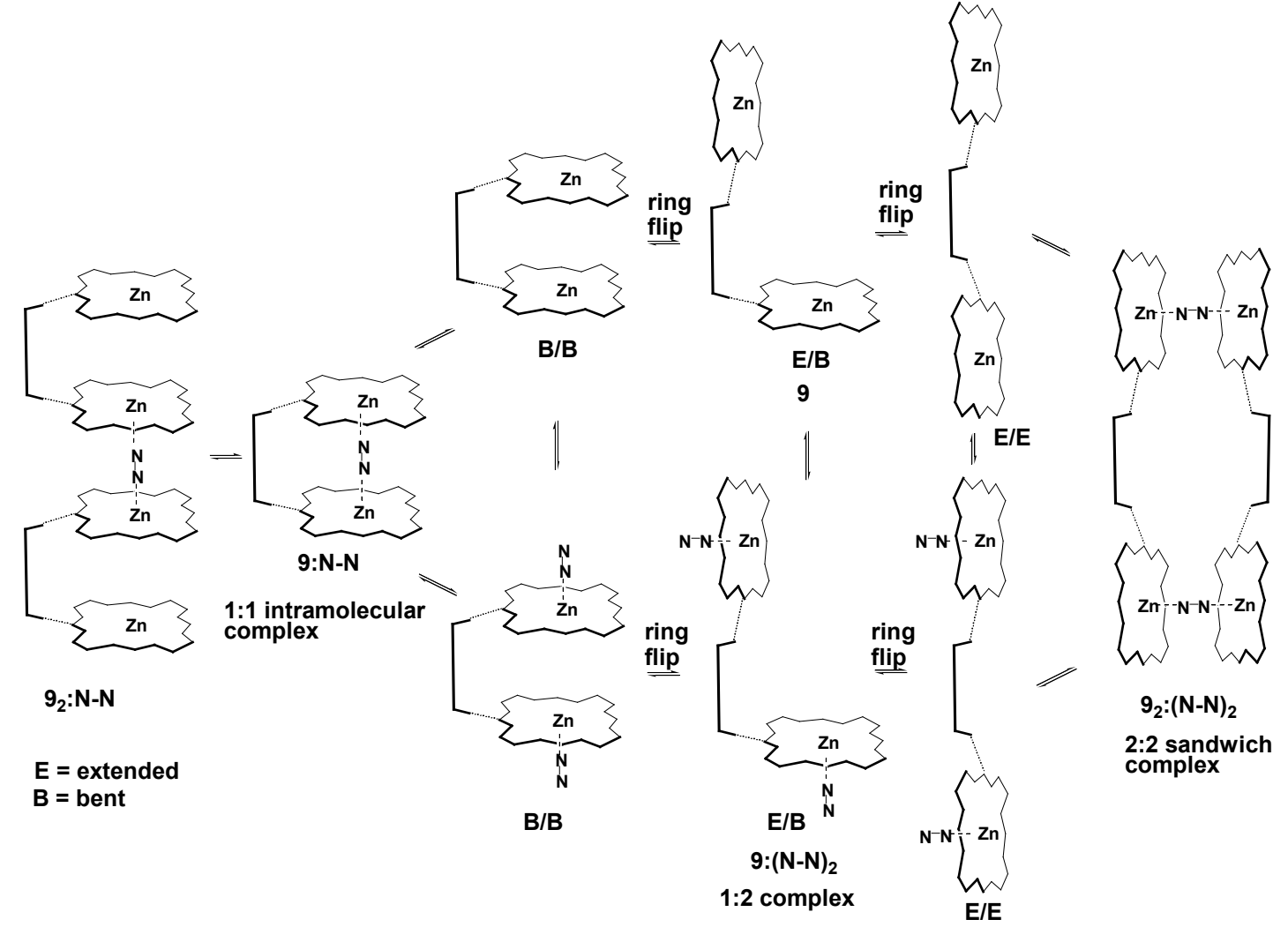

Scheme 1. Complexation equilibria involved in the coordination of diamines to 9 
Table 1. Binding constants $\left(K_{\mathrm{a}} / \mathrm{M}^{-1}\right)$ of 11 and 10 with propylamine and quinuclidine ${ }^{(\mathrm{a})}$

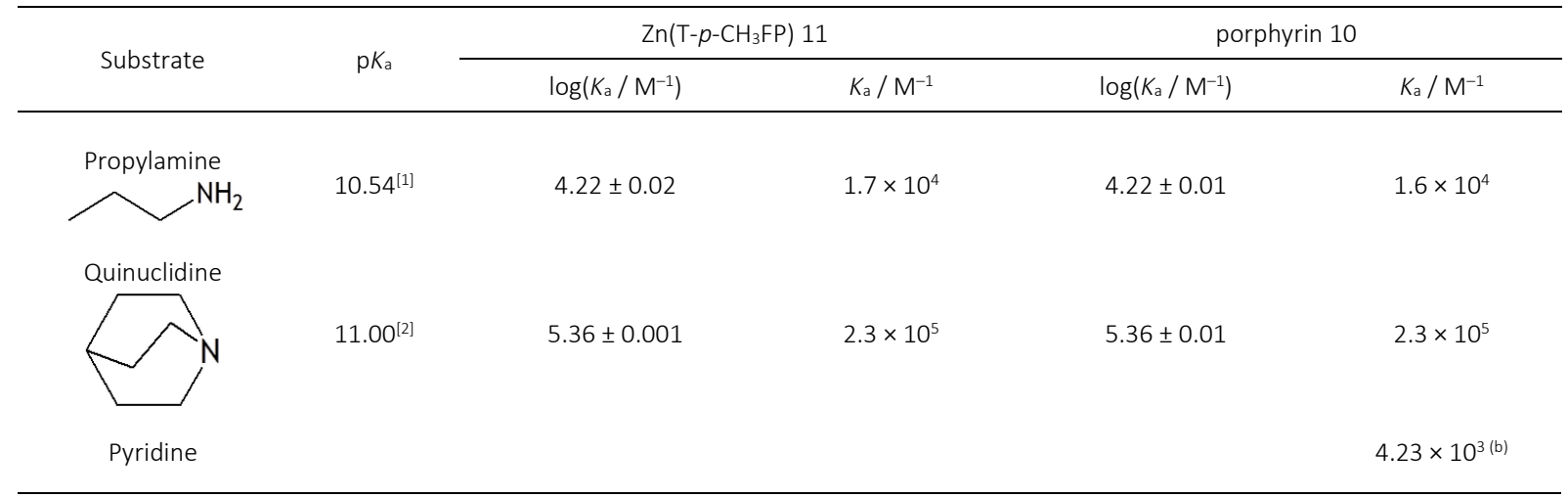

(a) UV-Vis, toluene, $298 \mathrm{~K}$.

(b) ZnTPP, Ref. [21].

determined, i.e. the flexibility of propyl linkers on the possibility for the adaptation of bis-porphyrin 9 for the complexation with diamines of various dimensions. Cyclic diamines (pyrazine, 4,4'-bipyridine and DABCO) are selected for this purpose on the basis of their differences in $\mathrm{p} K_{\mathrm{a}}$ values.

During titrations of bis-porphyrin 9 with a series of acyclic diamines $\mathrm{H}_{2} \mathrm{~N}\left(\mathrm{CH}_{2}\right)_{n} \mathrm{NH}_{2}, n=3-8$, a characteristic (a)

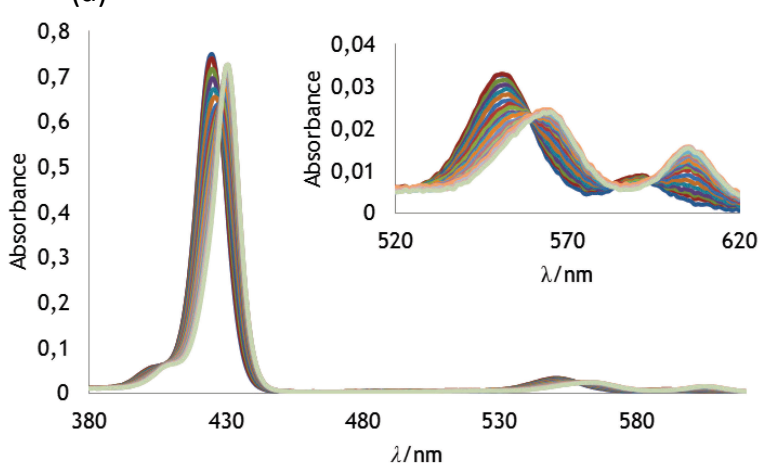

(b)

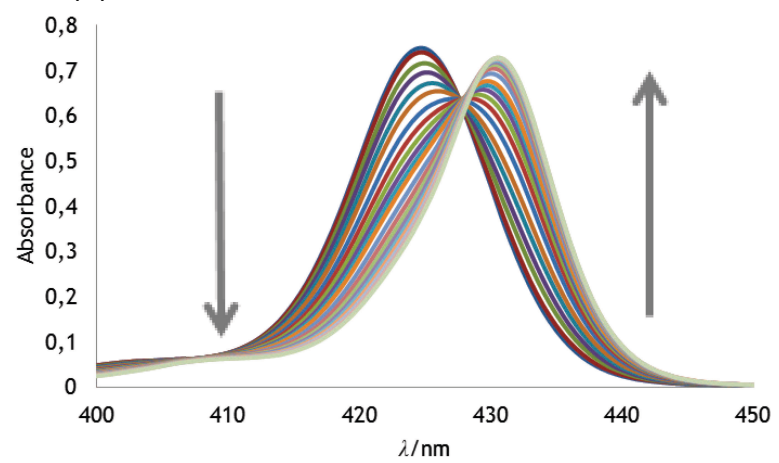

Figure 1. Changes in UV-Vis spectra of monoporphyrin $10(2 \mu \mathrm{M})$ by titration with propylamine $(0-135$ equivalents) in toluene at $298 \mathrm{~K}$ (a). Bathochromic shift of Soret band (b).

(a)

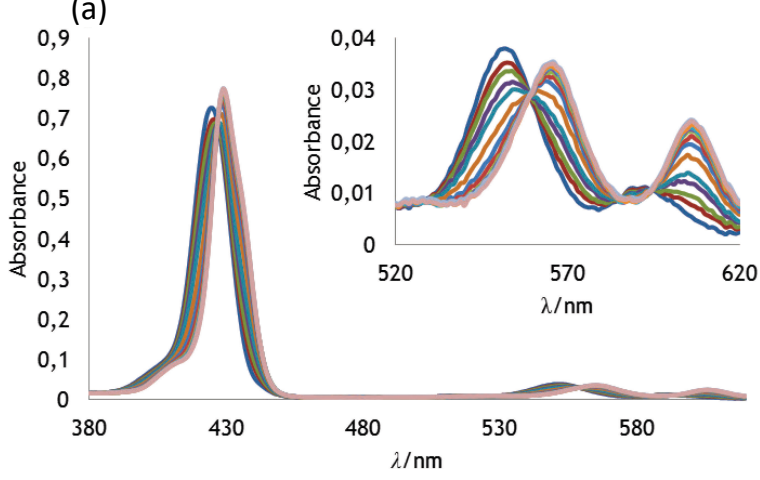

(b)

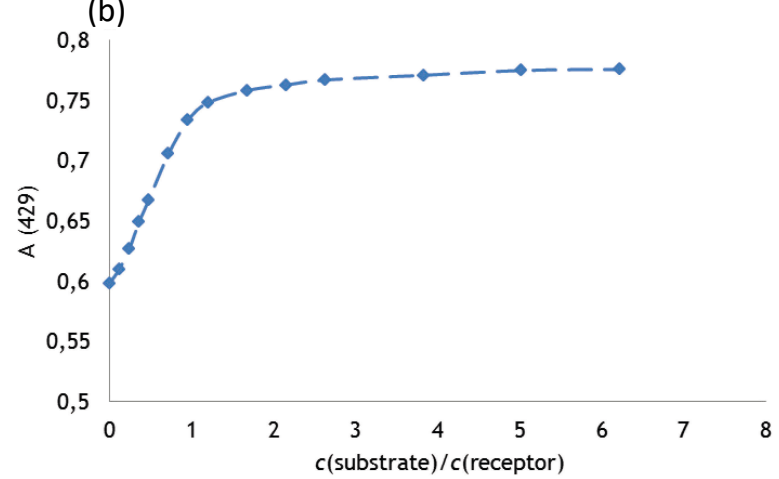

Figure 2. UV-Vis spectral changes (a) and titration curve (b) of bis-porphyrin $9(1.3 \mu \mathrm{M})$ in titration with $\mathrm{H}_{2} \mathrm{~N}\left(\mathrm{CH}_{2}\right)_{8} \mathrm{NH}_{2}(0-7$ equivalents) in toluene at $298 \mathrm{~K}$. 
bathochromic shift of Soret and Q bands was observed with clear isosbestic points, as shown in Figure 2. Maxima of Soret bands are within the range from 426 to $429 \mathrm{~nm}$ going from 1,3-diaminopropane to 1,8-diaminooctane, as given in Table 2, which differs from monoporphyrin 10 with maximum of complex at $431 \mathrm{~nm}$. In the case of 1,2-diaminoethane, maximum of Soret band remains at $425 \mathrm{~nm}$. These observations are in agreement with study published by Sanders ${ }^{[12]}$ which shows that two opposite effects are important in the change of maxima of Soret band. Amine binding to metalloporphyrin causes large bathochromic shift in comparison with free metalloporphyrin, whereas parallel geometry of chromophores in the case of bisporphyrins or under the angle up to $90^{\circ}$ causes a hypsochromic shift of maximum due to $\pi-\pi$ interactions. The exciton coupling ratio between the two chromophores decreases with the increase of the length of the diamine chain, i.e. with the increase of the distance of two chromophores, and the hypsochromic shift is smaller. Therefore, the shift of the Soret band changes almost linearly with the chain length of the diamine, Figure 3.

Spectral data processing with HypSpec program fits to the formation of 1:1 receptor-substrate complex of bisporphyrin 9 and acyclic diamines (A-A)@9. Other stoichiometries, such as 2:1 of substrate and receptor $(\mathbf{A}-\mathbf{A})_{2} @ 9$ were not obtained by spectrum processing. We did not observe these 2:1 complexes, since they could be obtained only in the presence of a very large excess of diamine guest. ${ }^{[6]}$ Analysis of titration data gave binding constants for 1:1 complexes of 9 and acyclic diamines, which are listed in Table 2. Bis-porphyrin 9 shows a high affinity towards aliphatic diamines with binding constants in the range from $3.7 \times 10^{5}$ to $1.4 \times 10^{7} \mathrm{M}^{-1}$. For comparison, the binding constant of monoporphyrin 10 with propylamine is smaller by one to three orders of magnitude $\left(1.6 \times 10^{4} \mathrm{M}^{-1}\right)$ indicating the positive cooperative binding of bidentate ligands within the cavity of bis-porphyrin receptor $9 .{ }^{[12]}$

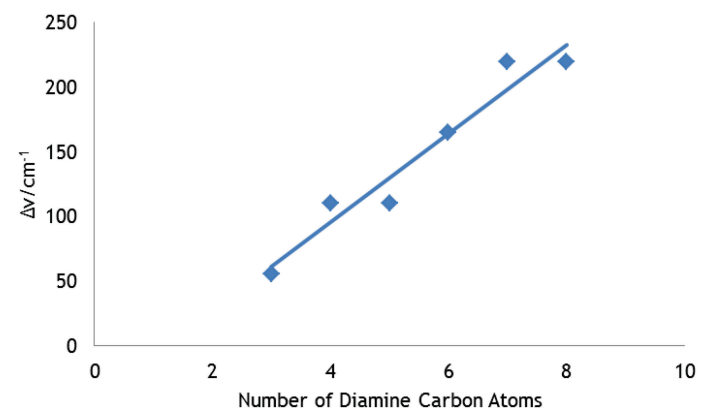

Figure 3. Changes of bathochromic shifts of Soret bands $\left(\Delta v / \mathrm{cm}^{-1}\right)$ of bis-porphyrin 9 in complexation with $\mathrm{H}_{2} \mathrm{~N}\left(\mathrm{CH}_{2}\right)_{n} \mathrm{NH}_{2}, n=3-8$ in relation to diamine chain length in toluene at $298 \mathrm{~K} ; \Delta v=v_{\text {free }}-v_{\text {complex }}$, where $v_{\text {free }}$ is the wavelenght of Soret band of free 9 and $v_{\text {complex }}$ is wavelenght of Soret band receptor-substrate complex at the end of titration.

Binding constant could be additionally increased by appropriate substrate size in receptor-substrate interactions, which indicates that among acyclic diamine substrates used in this study, $\mathrm{H}_{2} \mathrm{~N}\left(\mathrm{CH}_{2}\right)_{8} \mathrm{NH}_{2}$ best fits to receptor 9 . Due to entropic loss associated with binding of substrate to bis-porphyrin, $K_{\mathrm{a}}$ decreases by one order of magnitude for $\mathrm{H}_{2} \mathrm{~N}\left(\mathrm{CH}_{2}\right)_{n} \mathrm{NH}_{2}, n=4-7$. Further reduction of the chain of diamine results in an increase in entropy loss, and thus in reducing the binding constants for $\mathrm{H}_{2} \mathrm{~N}\left(\mathrm{CH}_{2}\right)_{n} \mathrm{NH}_{2}, n=2,3$ in comparison to $\mathrm{H}_{2} \mathrm{~N}\left(\mathrm{CH}_{2}\right)_{8} \mathrm{NH}_{2}$. With the assumption that allosteric cooperativity is near or equal 1 , chelate cooperativity was quantified via effective molarity (EM). It can be seen that majority of values fall in between $1 \mathrm{mM}$ and $25 \mathrm{mM}$ what is expected for similar systems. ${ }^{[24]}$ The largest EM was obtained for 1,8-diaminooctane, as expected for the bidentate guest with the highest $K_{\mathrm{a}}$.

As far as we are aware, there is no many literature examples of bis-porphyrin titrations with acyclic diamines in toluene. Binding constants reported in other solvents

Table 2. Soret band maxima of complex $\left(\lambda_{\max }\right)$ and binding constants $\left(K_{\mathrm{a}}\right)$ with corresponding $\mathrm{EM}^{(\mathrm{a})}$ of bis-porphyrin 9 with acyclic diamines of general formula $\mathrm{H}_{2} \mathrm{~N}\left(\mathrm{CH}_{2}\right)_{n} \mathrm{NH}_{2}(n=2-8)^{(\mathrm{b})}$

\begin{tabular}{|c|c|c|c|c|}
\hline Substrate & $\lambda_{\max } / \mathrm{nm}$ & $\log \left(K_{\mathrm{a}} / \mathrm{M}^{-1}\right)$ & $K_{\mathrm{a}} / \mathrm{M}^{-1}$ & $E M / \mathrm{mM}$ \\
\hline 1,2-diaminoethane & 425 & $5.57 \pm 0.07$ & $3.7 \times 10^{5}$ & 0.7 \\
\hline 1,3-diaminopropane & 426 & $5.74 \pm 0.08$ & $5.5 \times 10^{5}$ & 1.0 \\
\hline 1,4-diaminobutane & 427 & $6.27 \pm 0.08$ & $1.9 \times 10^{6}$ & 3.4 \\
\hline 1,5-diaminopentane & 427 & $6.59 \pm 0.05$ & $3.9 \times 10^{6}$ & 7.0 \\
\hline 1,6-diaminohexane & 428 & $6.21 \pm 0.06$ & $1.6 \times 10^{6}$ & 2.9 \\
\hline 1,7-diaminoheptane & 429 & $6.18 \pm 0.06$ & $1.5 \times 10^{6}$ & 2.8 \\
\hline 1,8-diaminooctane & 429 & $7.14 \pm 0.04$ & $1.4 \times 10^{7}$ & 25 \\
\hline
\end{tabular}

\footnotetext{
(a) Allosteric cooperativity is assumed to be $=1$.
}

(b) UV-Vis, measured in toluene at $298 \mathrm{~K}$. 
could not be directly compared to our results, since binding constants are highly dependent on solvent. ${ }^{[25]}$ For the titrations of bis-porphyrin 6 with a series of $\alpha, \omega$-diamines ranging from 1,2-diaminoethane to 1,6-diaminohexane, binding constants $K_{a}=1.9 \times 10^{8}, 1.7 \times 10^{8}, 1.6 \times 10^{8}, 6.1 \times$ $10^{7}$ and $3.7 \times 10^{7} \mathrm{M}^{-1}$, were obtained, respectively. ${ }^{[11]}$ Very large constants suggest that these ligands can coordinate by adjusting their conformation. 1,2-diaminoethane displays the largest affinity and this observation is explained by the reduction of the affinity of the larger diamines through a requirement for the loss of more internal motion on binding or the introduction of conformational strain upon binding. Monodentate guest hexylamine has much smaller binding affinity $\left(K_{a}=5.1 \times 10^{4} \mathrm{M}^{-1}\right)$, which is comparable to the $K_{a}$ values which we obtained in titrations of $\mathbf{1 0}$ and $\mathbf{1 1}$ with propylamine (Table 1). Our results for a series of $\alpha, \omega$-diamines show the opposite trend than in $\mathbf{6}$ and $K_{\mathrm{a}}$ for 1,8 -diaminooctane is the largest in the series. Since $\mathbf{9}$ is less rigid host than Crossley's system 6 possessing wider separation of two porphyrin moieties and could accommodate larger $\alpha, \omega$-diamines without the introduction of conformational strain upon binding. In general, obtained $K_{\mathrm{a}}$ values for 9 are by one or two orders of magnitude smaller than for 6 . On the other hand, Carofiglio ${ }^{[9]}$ obtained $K_{\mathrm{a}}$ values for association of bisporphyrins 3-5 (Chart 1 ) with $\mathrm{H}_{2} \mathrm{~N}\left(\mathrm{CH}_{2}\right)_{8} \mathrm{NH}_{2}$ guest in dichloromethane $\left(4.2 \times 10^{6}, 5.3 \times 10^{6}\right.$ and $5.2 \times 10^{6} \mathrm{M}^{-1}$, respectively). Since binding constants in dichloromethane are almost one order of magnitude larger than in toluene, [23] this indicates that bis-porphyrin 9 complexes to $\mathrm{H}_{2} \mathrm{~N}\left(\mathrm{CH}_{2}\right)_{8} \mathrm{NH}_{2}$ with binding constant which is almost two order of magnitude larger than constants reported for hosts 3-5.

The stoichiometry of the 1:1 receptor-substrate complex of bis-porphyrin 9 and $\alpha, \omega$-diamines was confirmed by ${ }^{1} \mathrm{H}$ NMR titration experiments. Concentrations which were used for NMR titrations are too high for determination of binding constants larger than $10^{4} \mathrm{M}$. A $0.001 \mathrm{M}$ solution of $\mathbf{9}$ in deuterated chloroform was titrated by addition of 1,3-diaminopropane, and changes in chemical shifts of NMR signals were monitored. Figure 4 depicts ${ }^{1} \mathrm{H}$ NMR spectra of free bis-porphyrin 9 and 1,3-diaminopropane. Signals of bis-porphyrin 9 are divided in two main regions: aromatic porphyrin signals between 7 and 9 ppm and bridge signals between 1 and 4 ppm.

Figure 5 shows the spectral changes caused upon the addition of up to 2.1 equivalents of 1,3-diaminopropane to $0.001 \mathrm{M}$ solution of bis-porphyrin 9. Addition of 0.3 equivalents of 1,3-diaminopropane shifts the aromatic signals of porphyrin to higher magnetic field with the accompanying broadening of signals (Figure 6). High field shift is ascribed to decreased distance between two porphyrinic rings during the complexation. ${ }^{[26]}$ The NMR proton signals of norbornane bridge are just slightly affected due to their distant position from the coordination site on porphyrin.

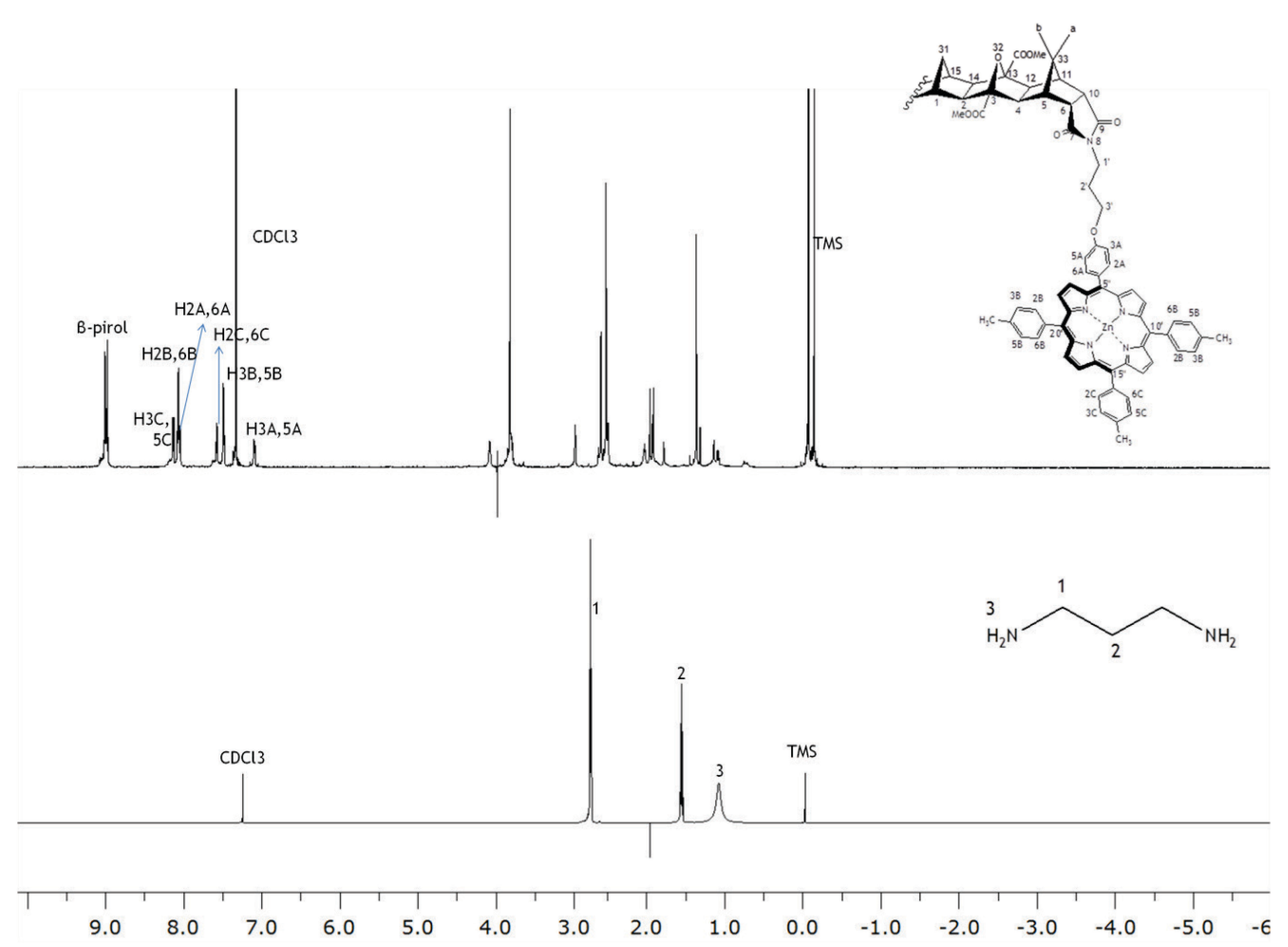

Figure 4. ${ }^{1} \mathrm{H}$ NMR spectrum of bis-porphyrin 9 and 1,3-diaminopropane. 
Further increase of concentration of 1,3-diaminopropane causes additional signal shifts to higher magnetic field and change in signal shape. Larger shift of complexed porphyrin to higher field by $0.3 \mathrm{ppm}$ in comparison to signals of free porphyrin could be noticed. There are no further changes of porphyrin signals when receptor/substrate ratio is higher than $1: 1$, which confirms $1: 1$ stoichiometry of complex. ${ }^{[24]}$

Simultaneously to the changes of ${ }^{1} \mathrm{H}$ NMR chemical shifts of the host $\mathbf{9}$, the addition of 0.3 equivalents of diamine shows that the protons of complexed 1,3-diaminopropane are broadened and strongly shifted towards higher field by $6.6 \mathrm{ppm}$ in comparison to protons of free diamine and appear at $\delta-4$ to $-6 \mathrm{ppm}$. This observation is rationalized by positioning of these protons between two porphyrinic rings with large magnetic shielding. ${ }^{[24]}$ These ${ }^{1} \mathrm{H}$ NMR shifts also indicate that nitrogen atoms of both amines coordinate to zinc. In the case of complex formation by only one nitrogen atom, significantly smaller chemical shifts are expected for diamine protons distant from the coordination site and the change of its symmetry. The increase of concentration of 1,3-diaminopropane from 0.6 to 0.9 equivalents causes small chemical shift of signals toward lower field due to increased amount of free 1,3-diaminopropane which protons are positioned at significantly lower field (Figure 5). Broad signals of 1,3-diaminopropane indicate that free and bound molecules of 1,3-diaminopropane are in rapid equilibrium. Above 1.2 equivalents of 1,3-diaminopropane added, the fast exchange equilibrium causes the coalescence of guest signals and which cannot be observed on the NMR time scale.

Titrations of bis-porphyrin 9 with pyrazine, 4,4'-bipyridine and DABCO resulted in similar UV spectral changes as in titrations with acyclic diamines, which indicates that cyclic diamines also form $1: 1$ receptor-substrate complex. Titration of 9 with 4,4'-bipyridine causes bathochromic shift of the Soret band with clear isosbestic point and new maximum at $428 \mathrm{~nm}$, with simultaneous bathochromic shift of $Q$ bands (Figure 7). Titrations with pyrazine and DABCO show similar bathochromic shift of $Q$ bands and isosbestic points (Figure 8). Soret band maximum for DABCO@9 complex remains at $425 \mathrm{~nm}$, whereas in the case of pyrazine@9 complex a hypsochromic shift of Soret band with maximum at $424 \mathrm{~nm}$ is observed. This difference could be explained in similar way as in the case of complexation of bis-porphyrin 9 with acyclic amines, exciton coupling caused by the proximity of the chromophore in the complex. Also, the Soret bands are narrowed to half the height of the complex relative to free 9 as a result of reduced conformational flexibility in the complex (Figures 7 and 8).

Spectrum processing with HypSpec program in the case of cyclic diamines also fits to the formation of $1: 1$ receptor-substrate complex of $\mathbf{9}$ and diamines. Other stoichiometry of receptor/substrate were not obtained. Titration data analysis gives binding constants for $1: 1$ receptor-substrate complexes of bis-porphyrin 9 and cyclic diamines which are listed in Table 3.

Changes during titration of bis-porphyrin 9 were significantly slower for pyrazine in comparison with 4,4'bipyridine and DABCO, which is in accord with obtained binding constants of $6.7 \times 10^{5} \mathrm{M}^{-1}$ for 4,4'-bipyridine@9 and $9.4 \times 10^{6} \mathrm{M}^{-1}$ for DABCO@9, as compared to $6.2 \times 10^{3}$ $\mathrm{M}^{-1}$ for pyrazine@9 (Table 3). With the increase of $\mathrm{p} K_{\mathrm{a}}$ values of cyclic diamines binding constants also increase. ${ }^{[23,27]}$ In comparison, the association of orthoand meta-bis-porphyrins 2 with DABCO gives sandwich $1: 1$ complexes with binding constants of $3.5 \times 10^{7}$ and $2.5 \times 10^{8} \mathrm{M}^{-1}$ in chloroform, respectively. ${ }^{[8]}$ For bis-porphyrin possessing 1,8-diethinylanthracene linker, Brettar obtained the $1: 1$ complexes with binding constants of $4 \times 10^{5}$ and $1 \times 10^{7} \mathrm{M}^{-1}$ for pyrazine and DABCO in dichloromethane. ${ }^{[25]}$ Since the binding constants ${ }^{[23]}$ in chloroform are by one order of magnitude smaller than in toluene, whereas in dichloromethane are larger by one order of magnitude, it indicates that Ballester's bis-porphyrins form more stable complexes with DABCO than bisporphyrin 9, whereas Brettar's bis-porphyrin complexes pyrazine by nearly one order of magnitude better than 9 and DABCO by one order of magnitude lower. Furthermore, for bis-porphyrin possessing bisacetylene linker, Sanders has obtained $1: 1$ complex with 4,4'-bipyridine with binding constant of $6 \times 10^{6} \mathrm{M}^{-1}$ in dichloromethane, which is comparable to $K_{\mathrm{a}}$ for $\mathbf{9}$ given in Table 3.[28]

In general, cyclic diamines have larger binding constants than aliphatic due to smaller repulsion between substituents and porphyrin macrocycle. Therefore, binding constant of $\mathbf{9}$ with DABCO is comparable to $K_{\mathrm{a}}$ for acyclic 1,8-diaminooctane, although 1,8-diaminooctane better geometrically fits to receptor by size ( $N-N$ distance) in comparison to $D A B C O$. This finding is rationalized in literature by higher chelating factor of DABCO. ${ }^{[30]}$ Chelating factor was also used to rationalize selectivity in complexation of $\alpha, \omega$-diamines. ${ }^{[31]}$

We were unable to obtain crystals of suitable for $\mathrm{X}$-ray diffraction analysis, therefore, the molecular modelling (semimepirical PM3 method) was employed to visualize the internal $1: 1$ complexes of bis-porphyrin 9 with diamines listed in Tables 2 and 3. Optimized structures indicate that $\mathbf{9}$ is a suitable host for bidentate ligands of various sizes. ${ }^{[32]}$ Complexes of 9 with 1,8-diaminooctane and 4,4'-bipyridine are shown as examples in Figure 9. A porphyrin centre-to-centre distance in these complexes is 12.2 and $11.3 \AA$, respectively. 


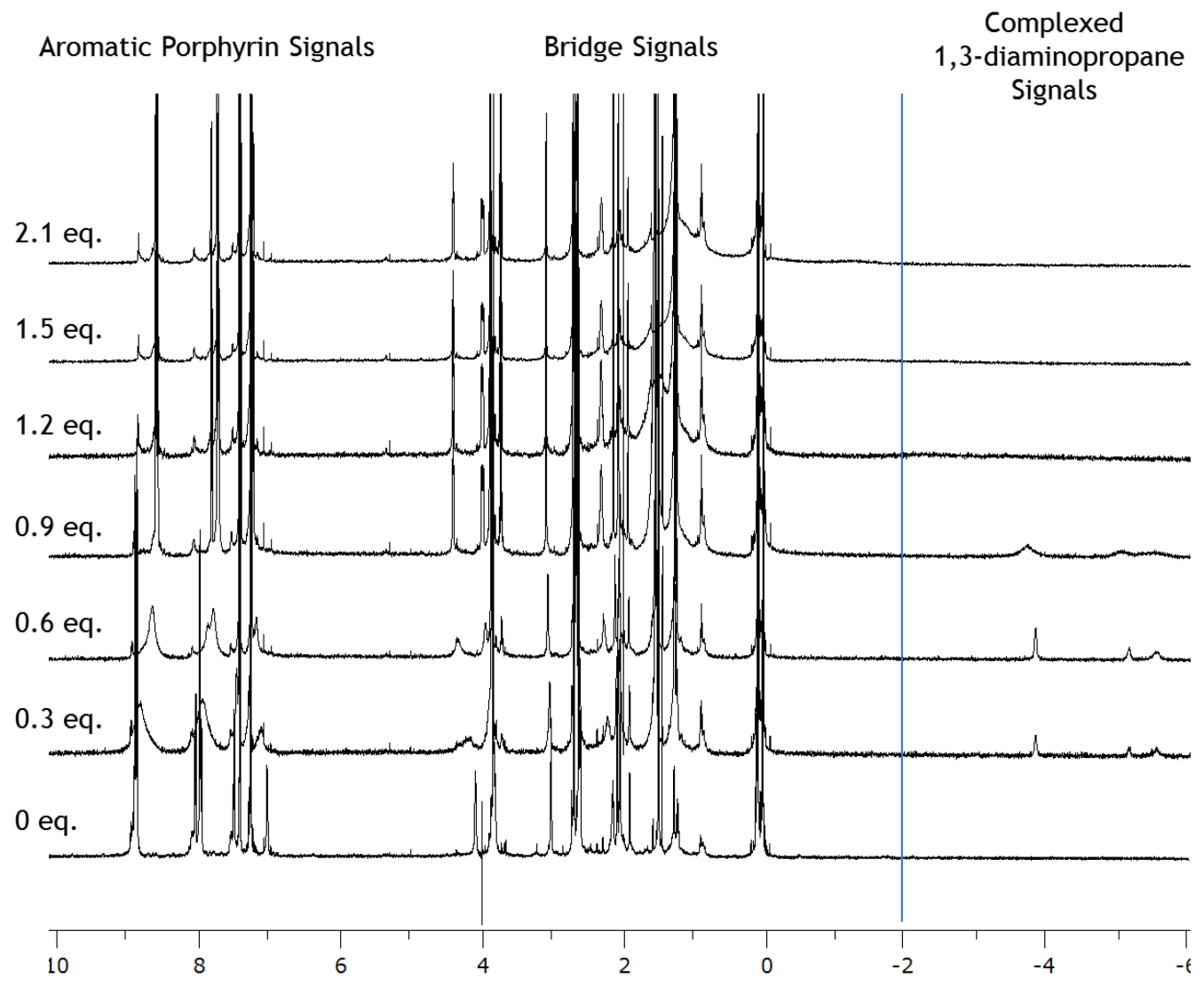

Figure 5. ${ }^{1} \mathrm{H}$ NMR titrations of bis-porphyrin $9(0.001 \mathrm{M})$ with 1,3-diaminopropane $(0-2.1$ equiv. $)$ in $\mathrm{CDCl}_{3}$.

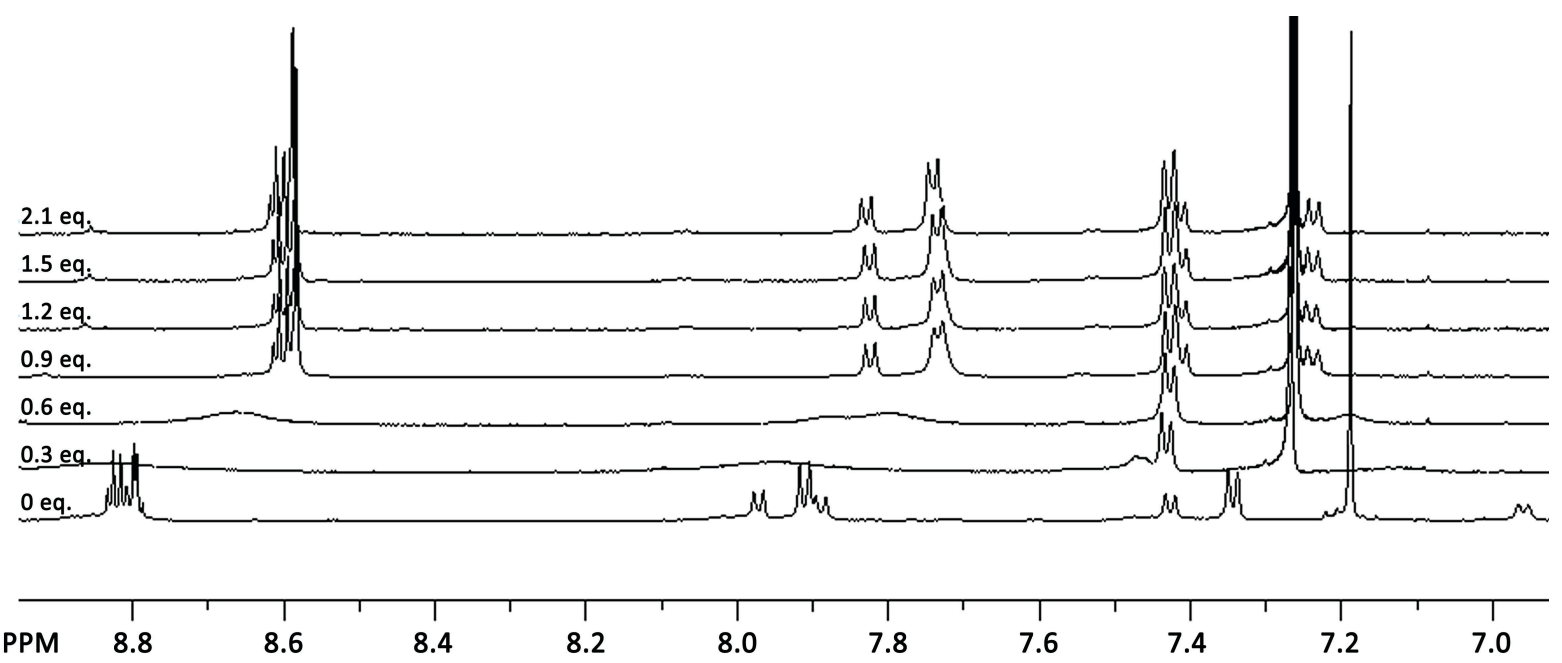

Figure 6. ${ }^{1} \mathrm{H}$ NMR change in aromatic signals of bis-porphyrin $9(0.001 \mathrm{M})$ with increasing amounts of 1,3-diaminopropane $\left(0-2.1\right.$ equiv.) in $\mathrm{CDCl}_{3}, 6.8-9.2 \mathrm{ppm}$ region. 
(a)

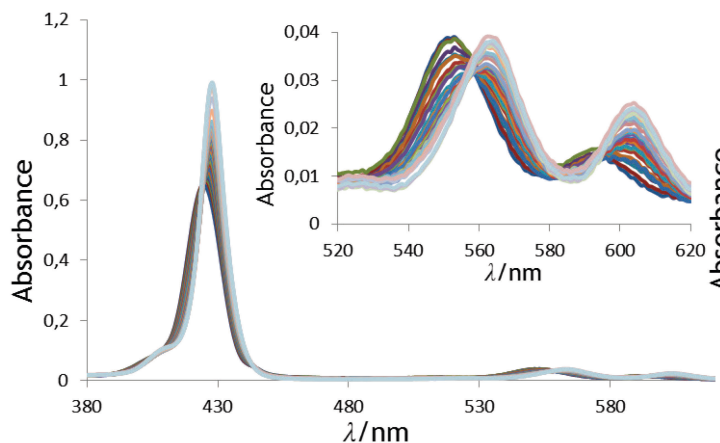

(b)

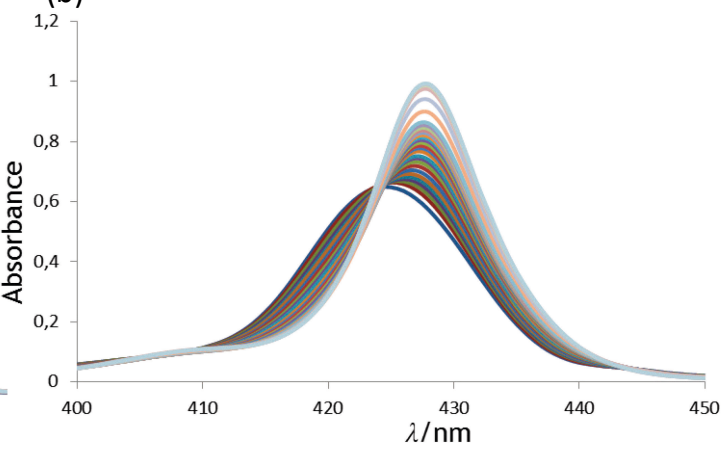

Figure 7. Changes of UV-Vis spectra of bis-porphyrin $9(1.3 \mu \mathrm{M})$ by titration with 4,4'-bipyridine $(0-11$ equivalents) in toluene at $298 \mathrm{~K}$ (inset depicts enlarged section with $Q$ band) (a); Bathochromic shift of the Soret band (b).

(a)

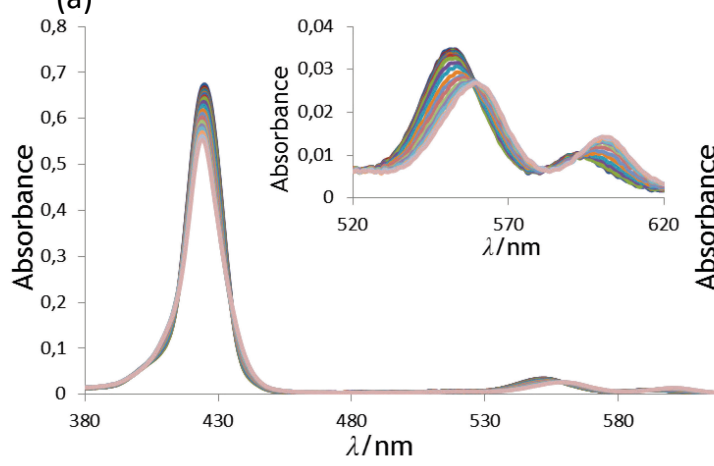

(b)

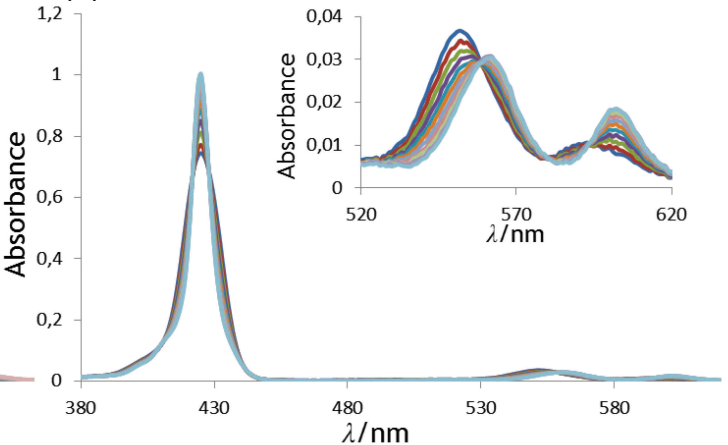

Figure 8. Changes of UV-Vis spectra of bis-porphyrin $9(1.3 \mu \mathrm{M})$ with pyrazine $(0-700$ equivalents) (a) and DABCO $(0-2$ equivalents) (b) in toluene at $298 \mathrm{~K}$ (Insets depict enlarged sections with $\mathrm{Q}$ bands).

Table 3. $\mathrm{p} K_{\mathrm{a}}$ values of substrates, maxima of Soret bands of complexes $\left(\lambda_{\max }\right)$ and binding constants $\left(K_{\mathrm{a}} / \mathrm{M}^{-1}\right)$ of 9 with cyclic diamines(a)

\begin{tabular}{l}
$K_{\mathrm{a}} / \mathrm{M}^{-1}$ \\
\hline Substrate
\end{tabular}

(a) Conditions: UV-Vis, toluene, $298 \mathrm{~K}$.

(b) $\mathrm{p} K_{\mathrm{a}}$ values in $\mathrm{H}_{2} \mathrm{O}$ at $25^{\circ} \mathrm{C}$, protonated cations are marked with $(+1),(+2)$ and given after $\mathrm{p} K_{\mathrm{a}}$ values 


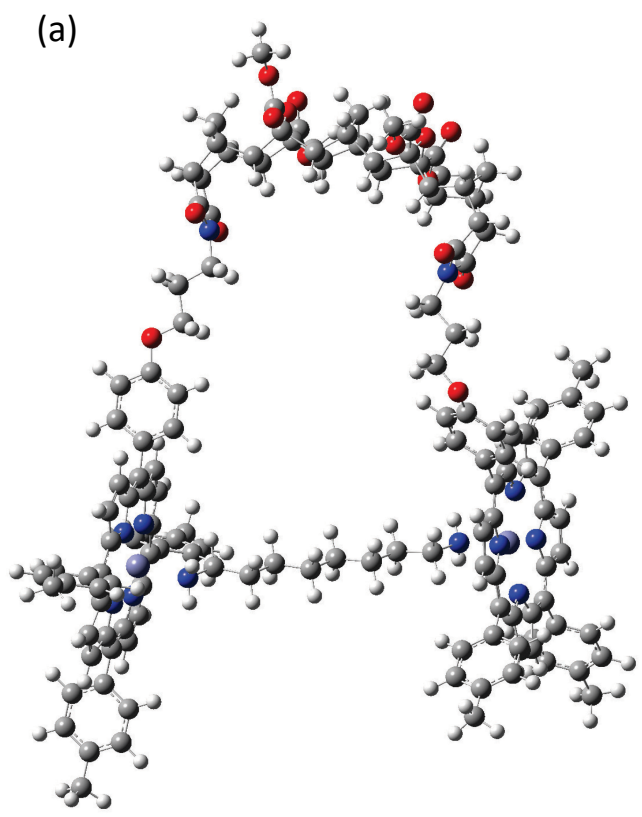

(b)

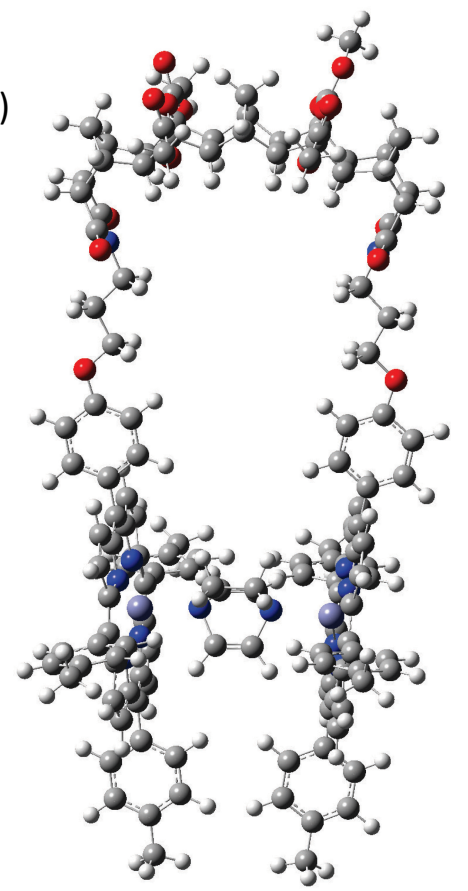

Figure 9. PM3 optimized structures of the internal 1:1 complexes: a) 1,8-diaminooctane@9 and b) DABCO@9.

\section{CONCLUSION}

UV-Vis titration studies revealed that polynorbornane bisimide linked bis-porphyrin tweezers 9 host effectively make complexes with ditopic aliphatic $\alpha, \omega$-diamine ligands. Obtained binding constants are large, ranging from $K_{a}=$ $3.7 \times 10^{5}$ to $1.4 \times 10^{7} \mathrm{M}^{-1}$ due to the positive cooperative binding of bidentate host. Some preference for binding of 1,8 -diaminooctane over shorter $\alpha, \omega$-diamines is experimentally demonstrated.

\section{EXPERIMENTAL SECTION}

Synthesis of compounds $\mathbf{9}, \mathbf{1 0}$ and $\mathbf{1 1}$ was reported previously. ${ }^{[15]}$ In all titration experiments the exact volume of the solvent was weighed on the analytical scale with an accuracy of $0.1 \mathrm{mg}$. UV-Vis titrations were carried out at a concentration of porphyrin solution of $10^{-6} \mathrm{~mol} \mathrm{dm}^{-3}$. Used solvents were of spectroscopic grade (Fluka). Aliquots of the substrate solution were added in the solution of porphyrin with known concentration. UV-Vis experiments were performed using a Varian Cary 100 UV-Vis spectrophotometer equipped with thermostat. All titrations were performed in $1 \mathrm{~cm}$ optical quartz cuvettes termostated at $25{ }^{\circ} \mathrm{C}$, and a correction for solvent was made. Obtained data were processed using commercial software for multivariate analysis HypSpec. Titration NMR experiments were performed using a Bruker Avance $600 \mathrm{MHz}$ NMR spectrometer.
Acknowledgment. We acknowledge the financial support of the Croatian Science Foundation (grant No. IP-2013-11-9310) and the Ministry of Science, Education and Sport of Croatia (grant No. 098-0982933-3218).

Supplementary Information. Supporting information to the paper is attached to the electronic version of the article at: http://doi.org/10.5562/cca3249.

\section{REFERENCES}

[1] D. Margetić, Curr. Org. Chem. 2012, 16, 829.

[2] C. A. Hunter, H. L. Anderson, Angew. Chem. Int. Ed. 2009,48, 7488.

[3] Beletskaya, V. S. Tyurin, A Y. Tsivadze, R. Guilard, C. Stern, Chem. Rev. 2009, 109, 1659.

[4] M. R. Johnston, R. N. Warrener, M. J. Gunter, Chem. Commun. 1998, 2739; b) M. R. Johnston, M. J. Latter, R. N. Warrener, Aust. J. Chem. 2001, 54, 633.

[5] N. Berova, G. Pescitelli, A. G. Petrovic, G. Proni, Chem. Commun. 2009, 40, 5958.

[6] R. B. Murphy, D.-T, Pham, S. F. Lincoln, M. R. Johnston, Eur. J. Org. Chem. 2013, 2985.

[7] R. M. Gomila, D. Quinonero, C. Rotger, C. Garau, A. Frontera, P. Ballester, A. Costa, P. M. Deya, Org. Lett. 2002, 4, 399.

[8] P. Ballester, A. Costa, A. M. Castilla, P. M. Deya, A. Frontera, R. M. Gomila, C. A. Hunter, Chem. Eur. J. 2005, 1, 2196. 
[9] T. Carofiglio, E. Lubian, I. Menegazzo, G. Saielli, A. Varotto, J. Org. Chem. 2009, 74, 9034.

[10] S. G. Telfer, T. M. McLean, M. R. Waterland, Dalton Trans. 2011, 40, 3097.

[11] M. J. Crossley, L. G. Mackay, A. C. Try, R. Walton, Chem. Commun. 1995, 1077.

[12] C. A. Hunter, M. N. Meah, J. K. M. Sanders, J. Am. Chem. Soc. 1990, 112, 5773.

[13] S. Norrehed, P. Polavarapu, W. Yang, A. Gogoll, H. Grennberg, Tetrahedron 2013, 69, 7131.

[14] S. Norrehed, H. Johansson, H. Grennberg, A. Gogoll, Chem. Eur. J. 2013, 19, 14631.

[15] Briš, P. Trošelj, D. Margetić, L. Flamigni, B. Ventura, ChemPlusChem 2016, 81, 985.

[16] D. Margetić, R. N. Warrener, D. N. Butler, D. Officer, Theor. Chem. Acc. 2007, 117, 239; (b) H. Tang, Z. Merican, Z. Dong, D. Margetić, Ž. Marinić, M. J. Gunter, D. Officer, D. N. Butler, R. N. Warrener, Tetrahedron Lett. 2009, 50, 667.

[17] R. N. Warrener, D. N. Butler, L. Liu, D. Margetić, R. A. Russell, Chem. Eur. J. 2001, 7, 3406.

[18] R. Mulholland, P. Thordarson, E. J. Mensforth, S. J. Langford, Org. Biomol. Chem. 2013, 10, 6045.

[19] D. D. Perrin, Dissociation constants of organic bases in aqueous solution, IUPAC Chem Data Ser, Buttersworth, London, 1965.

[20] N. M. Hext, J. Hansen, A. J. Blake, D. E. Hibbs, M. B. Hursthouse, O. V. Shishkin, M. Mascal, J. Org. Chem. 1998, 63, 6016 .
[21] N. Datta-Gupta, D. Malakar, R. G. Ramcharan, J. Inorg. Nucl. Chem. 1981, 43, 2079.

[22] S. Summers, A. M. Stolzenberg, J. Am. Chem. Soc. 1993, 115, 10559.; H. Imai, S. Nakagawa, E. Kyuno, J. Am. Chem. Soc. 1992, 114, 6719.

[23] D. Margetić, Physico-Chemical Properties of Organosuperbases in Superbases for Organic Synthesis: Guanidines, Amidines, Phosphazenes and Related Organocatalysts, (Ed. T. Ishikawa), Wiley, Chichester, 2009, pp. 9-48.

[24] P. Motloch, C. A. Hunter, Advances in Physical Organic Chemistry, 2016, 50, 77.

[25] Satake, Y. Kobuke, Tetrahedron 2005, 61, 13.

[26] T. Kurtán, N. Nesnas, F. E. Koehn, Y.-Q. Li, K. Nakanishi, N. Berova, J. Am. Chem. Soc. 2001, 123, 5974.

[27] J. Brettar, J.-P. Gisselbrecht, M. Gross, N. Solladie, Chem. Commun. 2001, 733.

[28] H. L. Anderson, S. Anderson, J. K. M. Sanders, J. Chem. Soc. Perkin Trans. 1 1995, 2231.

[29] J. A. Dean, Lange's Handbook of Chemistry, 15th Edition, McGraw-Hill, New York, 1998.

[30] G. Vaijayanthimala, V. Krishnan, S. K. Mandal, J. Chem. Sci. 2008, 120, 115.

[31] P. Danks, I. O. Sutherland, C. H. Yap, J. Chem. Soc. Perkin Trans. 1 1990, 421.

[32] M. R. Johnston, D. N. Lyons, Supramol. Chem. 2005, 17, 503. 